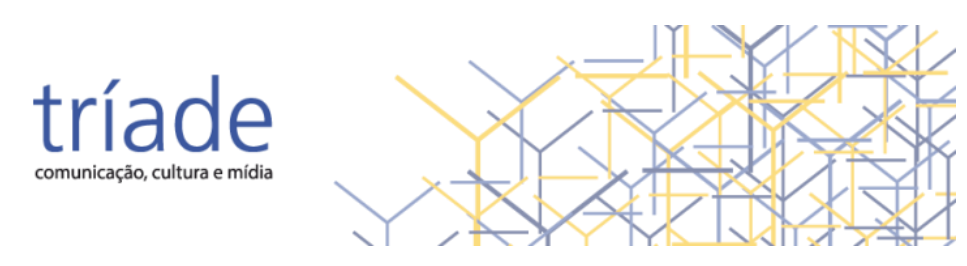

\title{
Na voz de um menino, o cinema e a epifania
}

In the voice of boy, cinema and epiphany

En voz de nino, cine y epifania

Rodrigo Oliva - Universidade Paranaense | Umuarama | Paraná | Brasil | prof.rodrigo.oliva@gmail.com I (1) https://orcid.org/0000-0003-4231-3892.

Resumo: A partir de uma conversa entre o cinema e a noção de epifania, este artigo destaca um possível lugar para pensar o que salta do universo potente e imaginário do cinema em poesia. Este diálogo é revelado a partir da análise da jornada do personagem principal do filme libanês Capharnaun, um menino que empenha uma via-crucis para conseguir o direito à cidadania. A tessitura desta reflexão se conecta as teorias da poesia do ritmo de Jean Epstein, aos debates sobre políticas das que saltam da obra que Jaques Ranciere, aos sentidos que emergem das telas por Thomas Elsaeser e Malte Hagener em diálogo com a produção de presença, conceito de Gumbrecht, que evoca nas potencialidades das representações que perpassam as materialidades do corpo, um possível lugar para as manifestações do discurso cinematográfico em estética e poesia.

Palavras-chave: Cinema. Política. Estética.

Abstract: Based on a conversation between cinema and the notion of epiphany, this article highlights a possible place to think about what jumps out of the powerful and imaginary universe of cinema in poetry. This dialogue is revealed from the analysis of the journey of the main character of the Lebanese film Capharnaun, a boy who works with a via-crucis to obtain the right to citizenship. The weaving of this reflection connects Jean Epstein's theories of rhythm poetry, to the political debates that leap out of the work that Jaques Ranciere, to the senses that emerge from the screens by Thomas Elsaeser and Malte Hagener in dialogue with the production of presence, concept by Gumbrecht, which evokes the potential of representations that permeate the materialities of the body, a possible place for the manifestations of cinematographic discourse in aesthetics and poetry.

Keywords: Cinema. Politics. Aesthetics.

4
6
6
0

Resumen: Basado en una conversación entre el cine y la noción de epifanía, este artículo destaca un posible lugar para pensar qué salta del universo poderoso e imaginario del cine en la poesía. Este diálogo se revela a partir del análisis del viaje del personaje principal de la película libanesa Capharnaun, un niño que trabaja con un via-crucis para obtener el derecho a la ciudadanía. El tejido de esta reflexión conecta las teorías de la poesía rítmica de Jean Epstein, a los debates políticos que saltan de la obra de Jaques Ranciere, a los sentidos que emergen de las pantallas de Thomas Elsaeser y Malte 
Hagener en diálogo con la producción de presencia, concepto de Gumbrecht, que evoca el potencial de las representaciones que impregnan las materialidades del cuerpo, un lugar posible para las manifestaciones del discurso cinematográfico en la estética y la poesía.

Palabras clave: Cine. Política. Estética.

Recebido em dezembro 2020 - Aprovado em dezembro 2020. 


\section{Introdução}

Este artigo apresenta um olhar analítico para alguns elementos teóricos que emergem de uma leitura sobre a imagem do cinema contemporâneo, a partir de uma reflexão sobre pontos que entrelaçam aspectos políticos e estéticos da imagem e suas potenciais representações, a partir do conceito de produção de presença. Tradicionalmente, os estudos teóricos do cinema são pontuais em traduzir aspectos ontológicos da imagem e suas instabilidades, bem como alinharse às perspectivas consagradas em dispositivos e publicações que destacaram teóricos e suas reflexões sobre o papel das escolas do cinema na história e sua representatividade.

Neste caso, proponho um caminho mais aberto a pensar o conceito de epifania proposto pelo teórico literário Hans Gumbrecht (2010), entrelaçando-o com aspectos da imagem e forma cinematográfica. Segundo o autor, em uma tradição que busca encontrar o lugar da materialidade, destoando de concepções hermenêuticas, do procedimentos e análises que se pautam pela produção de sentido. Como pensar o lugar da epifania na imagem cinematográfica? Esta apropriação do conceito é o foco desta análise que sinaliza a odisseia do garoto Zain, protagonista do filme líbano-frances, Capharnaun (2018), um lugar para entender o que desponta dos aspectos estéticos e políticos e a potência da imagem, quando da sua articulação com o sensível, a partir de uma cena específica do filme.

Para tanto, recupero alguns traços dos aspectos teóricos de Jaques Ranciere que, pensa os sujeitos políticos a partir de um referencial estético. São vários conceitos que perpassam o debate proposto pelo o autor, mas me interessa aqui pensar sobre a política da imagem e como esta ideia reforça aspectos que estão na base das representações dos corpos e das subjetividades que são apresentadas tanto em ficções, como 


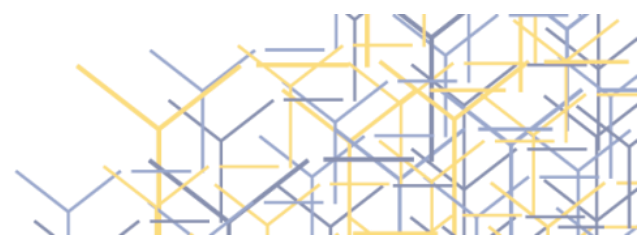

em filmes documentais.

Um dos focos é sobre os estudos do corpo, principalmente, quando pensamos o corpo como o local por onde se deslocam os atravessamentos que marcam estética e política. Por este viés, situamos os estudos teóricos do cinema a partir das referências sensoriais do corpo. O encontro com a obra de Thomas Elsaeser e Malte Hagener (2018), "Teoria do cinema: uma introdução através dos sentidos", nos estimula a pensar sobre como a imagem cinematográfica se relaciona diretamente às materialidades que estabelecem uma relação complexa e iminentemente agregada à potência de representação.

Portanto, neste artigo, apresento pontos de reflexões, traçando um caminho que deflagra maiores dúvidas do que estabelecimento de conclusões fechadas. Meu interesse é refletir e trazer pontos de discussão sobre os aspectos poéticos que entrelaçam as linguagens e, neste caso, a linguagem do cinema e seus aspectos poéticos inseridos nas imagens audiovisuais que despontam para um sentir, para um desarranjo de peles, e que problematizam uma epifania no audiovisual.

\section{Por Epifanias no Cinema}

O termo epifania, embora tratado sobre vários aspectos, tem sua divulgação em principais estudos nos âmbitos dos estudos literários e históricos, e será pautado nesta análise. É comum verificarmos pesquisas e análises que operam o termo a partir de textos e fundamentos da ação de personagens, cujo embate com o cotidiano cria momentos que os

(U) deslocam da realidade e traduzem um lugar dentro de uma concepção psicológica dos personagens, como se entrássemos em seus mundos vistos pelo olhar de um sujeito que partilha dos afetos provocados pelos textos.

Neste estudo, trago uma reflexão sobre a epifania, vinculada aos estudos de Hans Urich Gumbrecht $(2010,2015,2016,2012)$ que, a partir 


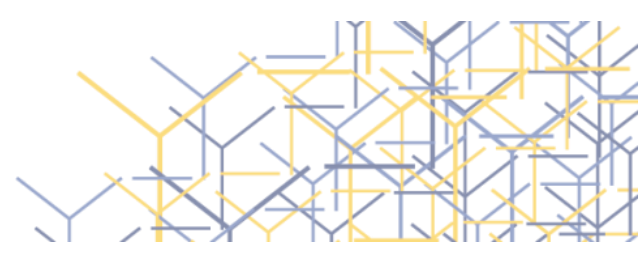

de uma abordagem cuja matriz se estabelece na fenomenologia e existencialismo, discute que epifania se molda a partir de uma tensão entre a produção de presença, a materialidade e a produção de sentidos. O autor, na obra "Produção de Presença", destaca o lugar da forma e seu valor diante dos processos de interações e representações, desmistificando uma tradição hermenêutica, principalmente na cultura ocidental, de supervalorização dos sentidos e significados numa ordem interpretativa do discurso.

Interessa-me pensar esta materialidade e como ela forma e potencializa a experiência estética. Nesse sentido, será problematizado neste texto o pensar a epifania como um lugar que provoca o lugar de encontro e potencia estética nos sujeitos dentro da imagem e naqueles que sentem os atravessamentos da imagem em suas peles. Segundo Gumbrecth (2010, p. 141), a experiência estética produz em nós uma sensação de intensidade, ela parece vir do nada, e decorre de uma temporalidade que se manifesta em um evento. Essa presentificação demarca os afetos que transbordam e operam as dinâmicas da nossa existência. Segundo Gumbrecht,

[...] há três aspectos que conferem ao componente de epifania, no âmbito da experiência estética, o estatuto de evento. Em primeiro lugar, [...] nunca sabemos se ou quando ocorrerá uma epifania. Em segundo lugar, quando ocorre, não sabemos que intensidade terá: não há dois relâmpagos com a mesma forma, nem duas interpretações de orquestra, com a mesma composição, que ocorram da mesma maneira. Finalmente (e acima de tudo), a epifania na experiência estética é um evento, pois se desfaz como surge. (GUMBRETCH, 2010, p. 142). SUrge. (GUMBRETCH, 2010, p. 142).

O autor discute a presentificação do tempo como uma categoria que atravessa a nossa existência, a partir de respostas e ações com o passado e com o futuro. Esse desejo de presentificação é visível a partir dos regimes de espacialidade. São eles que situam, emergem e vinculam o 
passado por meio de artefatos e imagens e ampliam a simultaneidade com o presente. Esta espacialidade é abordada por Gumbretch em outro texto chamado "Nosso amplo presente", onde o autor pontua que a linguagem consegue produzir epifanias, por meio de sua presença física ou, como afirma o autor, o entendimento da linguagem como a casa da presença e suas denotações espaciais (GUMBRETCH, 2015, p. 30-31).

Pensar o conceito de epifania a partir do regime estético da imagem cinematográfica me faz refletir sobre dois eixos. Primeiramente, um deslocamento interno dos filmes, numa concepção da ideia de epifania como representação dos sujeitos que fazem parte do local da diegese do filme. Que momentos se constituem em acontecimentos, deslocam personagens e a partir de uma faisca da realidade são interpelados por uma sensação. Por outro lado, ao colocar como sujeitos espectadores, como determinadas imagens são carregadas de potencias estéticas que assolam nos sujeitos essa ruptura, essa eventualidade que provoca esse efeito de presença.

No filme Capharnaüm (2018), a cineasta Nadine Labak apresenta uma construção narrativa cuja poética se estabelece a partir de uma jornada heróica de um menino, Zain. O garoto é interpelado por uma série de acontecimentos e situações que o colocam em situação de vulnerabilidade perante os conflitos sociais que assolam a territorialidade do Líbano e suas relações políticas. Nesta jornada, as percepções do garoto serão atravessadas por meio de um olhar maduro, singular, poético, em cuja travessia serão incorporados outros personagens como a imigrante africana e seu o bebê, os pais conservadores, a morte de irmã

(U) querida. O filme tem um aspecto de discussão política e civil e suas responsabilidades perante o universo frágil e esse conteúdo nos assola com efeitos poéticos, que deflagram espacialidades em efeitos de presença. 


\section{3 o cinema entre o sensível e o corpo}

Os textos de Jean Epstein pontuam alguns aspectos da linguagem cinematográfica, cuja reflexão se situa em textos reflexivos e abertos que promovem um ato de pensar o cinema por meio de abordagens de natureza filosófica, trazendo algumas aproximações com a literatura, contribuições sobre os aparatos tecnológicos, contextualizados no momento das vanguardas cinematográficas. Eptein é, sem dúvida, um dos primeiros pensadores da imagem cinematográfica, a discutir a poética do ritmo e do tempo cinematográfico. Isto posto já sinaliza um local para pensar e evidenciar o cinema a partir de expressões estéticas, cuja natureza se pauta pelos atravessamentos, cuja forma não se vincula diretamente à espacialidade $e$ às representações figurativas que amplamente foram discutidas na história do cinema.

[...] Um outro mérito surpreendente do cinema é 'multiplicar e abrandar intensamente os jogos de perspectiva temporal, levando a inteligência para uma ginástica que lhe é sempre penosa: passar de absoluto arraigado a instáveis condicionais. (EPSTEIN, 1983, p. 289).

Para Epstein (1983), o lugar da materialidade cinematográfica é atravessada pela poética do ritmo. Cinema é ritmo, a partir de considerações sobre esta imersão de uma temporalidade e de marcações que se estabelece a partir do uso de elementos do código cinematográfico, como as técnicas do enquadramento, aproximação e distribuição de especialidades e temporalidades que permeiam esse local de uma poética que opera na produção de presenças e efeitos do sensível.

Thomas Elsaeser e Martin Hagener (2018) traduzem os aspectos teóricos do cinema a partir de relações diretas com o corpo e suas implicações no sensível para pensar o cinema a partir de suas co-relações com os órgãos de sentido que assolam a estrutura corporal que marca este estudo. A analogia estabelecida pelo autores perpassa esses 
caminhos, evidenciando estruturas para pensarmos o jogo teórico, que, a meu ver, se traduz num jogo poético entre teoria e sensível. Em todos os aspectos, os atravessamentos partem de aspectos que interseccionam a corporalidade:

\begin{abstract}
A superficialidade do filme - frequentemente a representação de uma superfície hapticamente carregada, tal como o close-up de um corpo (por exemplo, uma pele de animal, cabelos ou pelos arrepiados) ou de qualquer outra textura chamativa e evocativa (incluindo a tangibilidade do próprio filme) - pode, em sua materialidade revelar lembranças que estavam virtualmente presentes, mas precisavam do filme para concretizadas. (ELSAESER; HAGENER, 2018, p. 141).
\end{abstract}

Nesse sentido, destaco um espaço discutido nesta obra, ou seja,de pensarmos o cinema pelo atravessamento de experiências que assolam o nosso encantamento e o sentir a imagem. Imagens que potencializam um arranjo sensível, cuja produção e articulação estabelecem uma conexão com o fílmico que assola nossos espaços e, principalmente, nossas peles. Muito se pensa sobre este lugar da produção e vinculação da materialidade nos debates fílmicos. Acredito ser relevante pensar este lugar do sensível, que atravessa o lugar dos sentidos, cuja abordagem me parece ainda hegemônica e, muitas vezes, pouco compreendida, principalmente para os estudos que se pautam em articulações rígidas e pouco poéticas que destacam a produção do sentido como modelo.

\title{
4 Um corpo estético e político
}

No filme Capharnaun, vemos Zain por meio da representação de um corpo. Um corpo de criança, frágil, singular, pequeno, mas Seguro e grande em atitude. Esse corpo é, ao longo das duas horas de filme, interpelado por uma série de eventos, acontecimentos e cruzamentos com a vida adulta. É por meio desta jornada que, somos instalados dentro do 


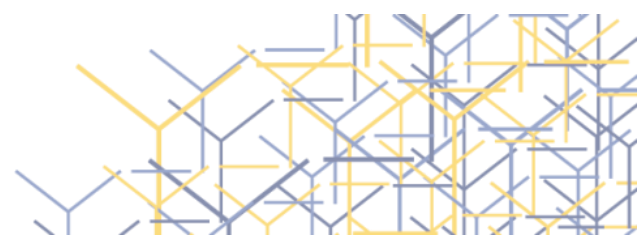

filme, acompanhando o ritmo da vida e aventura do garoto e sua jornada em rumo de algo. Em meio a essa aventura salta um corpo político, pois em todos os lugares por onde Zain passa, há uma esfera do político.

Jaques Ranciere destaca o lugar da filosofia política, a partir de variados termos como partilha do sensível, sujeitos do dissenso, entre outros. Variadas pesquisas destacam os conceitos do autor, principalmente em configurações dos sujeitos e atos políticos ligados a expressões em movimentos artísticos e sociais. Arrisco-me a trazer o pensamento do autor para uma análise de cenas de um filme de caráter narrativo, como Capharnaum, discutindo o termo política da imagem, para pensar o lugar do estético em consonância com os aspectos políticos que transpassam as reflexões da ordem dos regimes estéticos e simbólicos.

[...] Cinema, fotografia, vídeo, instalações e todas as formas de performance do corpo, da voz e dos sons contribuem para reconstruir o âmbito de nossas percepções e o dinamismo dos nossos afetos. Com isso, abrem passagens para novas formas de subjetivação política. (RANCIERE, 2012, p. 81).

Identificar esses pontos de ativismo politico por meio das representações faz parte do tratamento metodológico teórico de articulação entre as potências das imagens. Na obra de Ranciere, o estético e o político regem-se em dimensões compartilhadas. Neste sentido, pensar a política se desdobra em identificar essas rachaduras que deformam lugares onde prevalecem sistemas hegemônicos. A atitude política interna ou externa e as imagens se organizam a partir de um local

(1) que se desdobra e se desloca a partir da ação de uma subjetividade que desestabiliza os regimes do sensível.

A Atividade política é aquela que desloca um corpo do lugar que era designado ou muda a destinação de um lugar: ela faz ver o que não cabia ser visto, faz ouvir o discurso ali onde só tinha lugar o ruído, faz ouvir como discurso o que era só ouvido como ruído. (RANCIERE, 2018, p. 43). 
Ao verificar os espaços pelos quais o personagem Zain percorre em sua trajetória como protagonista no filme Capharnaun, verifica-se arquiteturas insólitas cujas bases mostram os regimes fechados da cultura e os enfrentamentos transculturais. O corpo do garoto é interpelado pelo corpo da personagem refugiada etíope Rahil. Ambos encontram-se e suas jornadas acabam tornando-se parte de um mesmo fluxo. Como dançantes da estrutura complexa de uma sociedade caótica, os dois personagens encontram em si um lugar para sobreviver. As cenas de Zain cuidando do filho de Rahil, o bebê Yonas, evidenciam o lugar dos embates culturais que, no universo das crianças, tornam-se potentes para deslocar o debate sobre os confrontos de natureza étnica. No universo das crianças, este choque se consubstancia em sensação e afetos que nos deslocam também. As cenas de Zain puxando Yonas por um balde evidenciam estes espaços e deslocamentos.

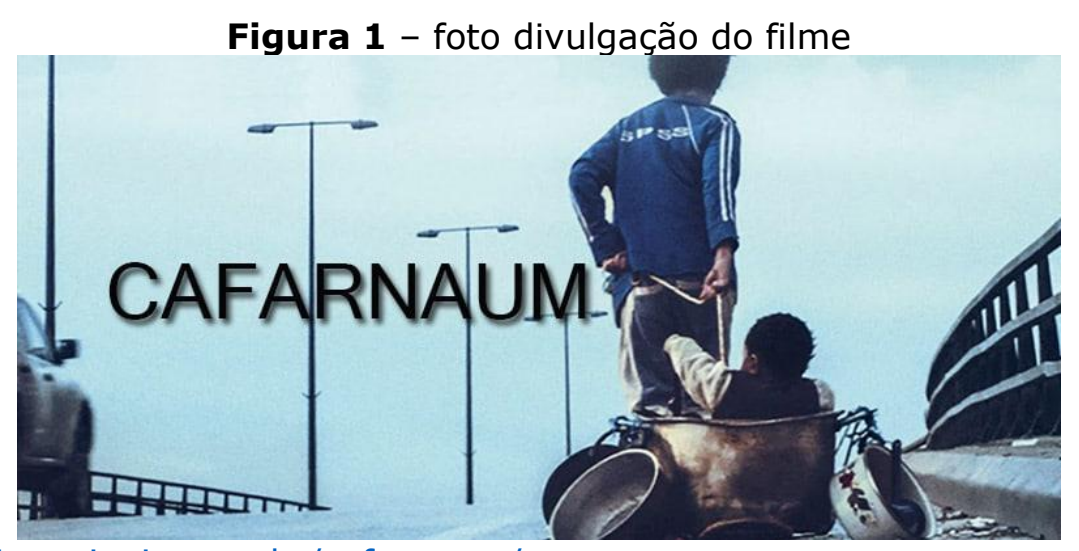

Fonte: www.cinegoiania.com.br/cafarnaum/.

\section{Capharnaum: a voz de um menino reflete o estético e o político}

Nesta reflexão, cuja articulação procura identificar e problematizar as artimanhas do estético e do político na imagem cinematográfica, focalizo a discussão em uma cena do filme Capharnaun. Esta cena é apresentada no final do filme. Após a revelação da morte da irmã, Zain comete um delito e vai preso numa instituição para menores infratores. 
Vemos imagens que denunciam como é o sistema prisional libanês. Neste espaço, assaltado pela ideia de se pronunciar frente a toda comunidade e na iminência de falar, Zain articula sua fala a partir de uma programa de televisão. Dentro do presídio, ele faz uma chamada telefônica para o programa de televisão. A atitude do garoto, quando percebida pela população da prisão, gera um motim no presidio. Vemos imagens e ouvimos a seguinte mensagem:

Eu quero processar os meus pais. Quero que os adultos me ouçam. Que aqueles que não tem como criar um filho, não os tenham. Do que eu vou me lembrar? Da violência? Dos gritos? Dos palavrões? Das correntes? Das cintas? Das chineladas? As palavras mais doces eram: sai daqui filho da puta! A vida é uma droga! A vida não vale bosta nenhuma! Vivo num inferno aqui!. Estou assando como um frango no espeto. A maior injustiça é a vida. Eu achava que seria uma boa pessoa, queridos por todos, mas o todo poderoso quis outra coisa. Ele prefere que a gente seja capacho do outro.

Figura 2 - cena do tribunal

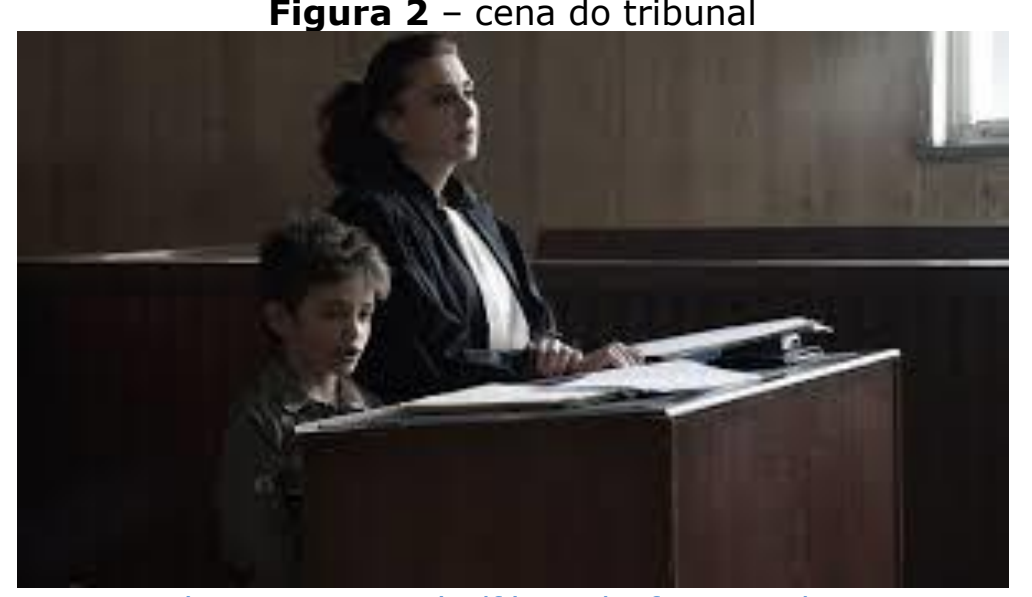

Fonte: https://www.papodecinema.com.br/filmes/cafarnaum/.

A cena tem uma articulação temporal marcante. Ouvimos a voz do personagem Zain, concatenada com imagens que mostram os problemas sociais agravantes do sistema carcerário libanês. Um policial leva Zain ao encontro da advogada e no encerramento da fala, no tribunal, vemos Zain em um embate com a própria mãe. Esta caminhada do personagem, em 
voz e imagem, é a corporeidade em manifesto, que condensa os aspectos políticos e estéticos que, em Capharnaum, são os motivos que enredam o espectador. Esta cena é empática, em um condensamento de tempo e de espaço, que projeta um lugar marcante da potência do estético e da forma.

Neste espaço, vemos como o personagem Zain é potencialmente estético e ao mesmo tempo político. Um corpo de criança que se desloca em espaços cuja penetração é improvável. É essa mobilização que carrega o imaginário de ato de manifesto, um ato político que grita. Solicitar aos pais que não tenha mais filhos é o jogo da responsabilidade social. Aos olhos de um adulto ou de alguém longe da cultura libanesa pode parecer incomum. Todavia, aos olhos daquele estar, uma criança clamar pela cidadania adquire um valor transcultural. Essa universalidade que acompanha o personagem naquilo que mais nos assalta que é o preenchimento dos vazios que operam nossos destinos. E quando Zain sorri para a câmera fotográfica que vai estampar sua imagem em sua identidade e sorri para todos que estão sendo cúmplices da sua jornada, seu ato torna evidente a potência do estético em coadunação com o político.

\section{Considerações finais}

O embate teórico proposto neste artigo tem como ponto principal pensar o lugar do estético e do político como potência para as representações. Algumas articulações teóricas podem parecer um pouco

(U) ilógicas. Todavia, o filme Capharnaun levanta alguns aspectos que me parecem importantes onde se articulam poesia, estética e política. Trazer Gumbretch para pensar esse local da estética, a partir do conceito de produção de presença e epifania, é pensar em situar um local de atravessamentos que iguala o lugar da forma e não somente do conteúdo, que vem sendo tratado com predominância em nossas pesquisas. A 


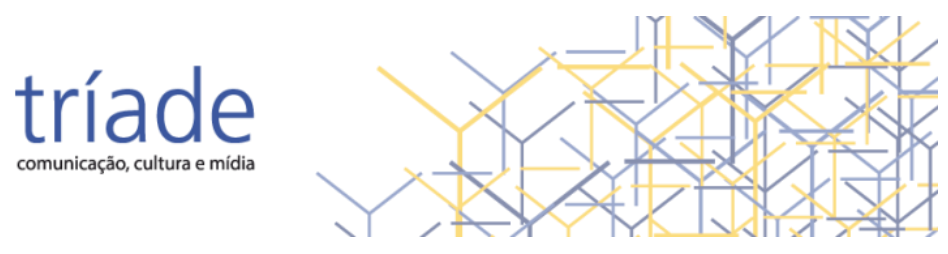

política da imagem em Ranciére é um caminho aberto para enfrentamentos sobre o lugar da estética e sua articulação com o político. O desentendimento e o ato político que deslocam corpos e promovem atos são pontuados pelo autor, a partir de regimes cujas marcas são o sensível.

Muito embora as teorias do cinema se articulam com modelos bem definidos, os estudos do corpo para pensarmos a imagem e suas potencias me fazem pensar sobre possíveis articulações com os efeitos da materialidade cinematográfica, principalmente a partir das poéticas do ritmo enfrentadas por Jean Epstein. Na articulação estética promovida pela diretora do filme Capharnaum, vemos como esta produção de formas ganha espaço frente a produção de sentidos na cena final analisada.

Portanto, esta reflexão pauta-se em problematizar aspectos que produzem o estético como um local para se pensar a potência da imagem cinematográfica, a partir de um componente político. Na representação da cena analisada, vemos o corpo e a voz do personagem Zain se deslocar, numa atitude desafiadora, infiltrado num sistema penal. O garoto salta sua voz para denunciar os abusos de um sistema patriarcal que assola crianças em muitos mundos. Uma voz de criança em busca de cidadania, clamando por responsabilidade fraterna. Essa inquietação atravessou minha pele e provocou enorme empatia comigo em uma sessão inteira, em uma tarde, em um cinema em São Paulo. Em meio a aplausos catárticos, a tela que caminhava para o inevitável final da projeção, me acendeu uma faísca, uma sensação em forma de epifania, que me colocava naquele espaço que atravessava o corpo deste garoto e o meu e

<U me fez sair do cinema em lágrimas, juntamente com outros seres que eu nem conhecia. 


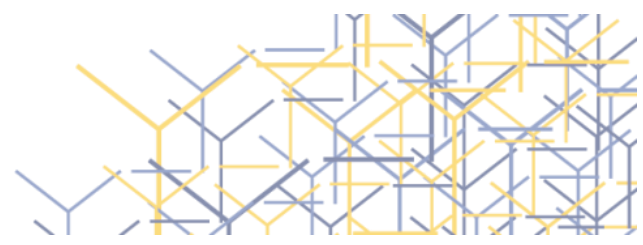

\section{Referências}

ELSAESER, T.; HAGENER, M. Teoria do cinema: uma introdução através dos sentidos. Campinas: Papirus, 2018.

EPSPTEIN, J. A inteligência de uma máquina. In: XAVIER, I. (Org.). A Experiência do Cinema. Rio de Janeiro: Graal, 1983.

GUMBRECHT, H. U. Produção de presença: o que o sentido não consegue transmitir. Rio de Janeiro: Ed PUC RIO, 2010.

GUMBRECHT, H. U. Nosso amplo presente. O tempo e a cultura contemporânea. São Paulo: Editora da UNESP, 2015.

GUMBRECHT, H. U. Serenidade, presença e poesia. Belo Horizonte: Relicários Edições, 2016.

GUMBRECHT, H. U. Graciosidade e estagnação. Rio de Janeiro: Contraponto: Editora PUC/RJ, 2012.

RANCIERE, J. O desentendimento: politica e filosofia. São Paulo: Editora 34, 2018.

RANCIERE, J. O espectador emancipado. São Paulo: Martins Fontes, 2012.

\section{Sobre o autor:}

Rodrigo Oliva - Doutor em Comunicação e Linguagens pela Universidade Tuiuti do Paraná. Professor e Pesquisador da Universidade Paranaense, nos Cursos de Publicidade e Propaganda e Tecnologia em Produção Audiovisual. 